\title{
Molecular Detection of Diverse Leifsonia Strains Associated With Sugarcane
}

Anthony J. Young, Centre for Crop Health, University of Southern Queensland, Toowoomba, Queensland, Australia; and Catherine J. Nock, Southern Cross Plant Science, Southern Cross University, Lismore, NSW, Australia

\begin{abstract}
Leifsonia xyli subsp. xyli, causal agent of ratoon stunting disease (RSD) of sugarcane (Saccharum interspecific hybrids), is the most well-known member of the Microbacteriaceae genus Leifsonia. However, the presence of other Leifsonia strains associated with sugarcane has not been reported. A total of 697 Australian and 40 Indonesian sugarcane fields were screened by leaf sheath biopsy (LSB) PCR using primers specific for $L$. $x y l i$ subsp. $x y l i$, in addition to primers designed to amplify DNA from other members of the genus Leifsonia. While L. xyli subsp. xyli was detected in 126 fields, a total of 37 distinct and novel Leifsonia and nonLeifsonia strains were detected in 116 fields. Representatives of these strains were also detected in multiple samples of expressed xylem sap.

Sequencing and phylogenetic analyses demonstrated the presence of a broad complex of novel Leifsonia strains, in addition to strains closely related to the recently erected Cnuibacter genus. Attempts to isolate Leifsonia strains were unsuccessful; however, one strain related to Cnuibacter was recovered from expressed xylem sap. Among the genetically diverse lineages discovered, identical genotypes were present in multiple sugarcane varieties growing in disparate regions in different years, strongly suggesting an ongoing association with sugarcane. The epidemiological significance of these strains is unknown, but there is evidence that they can interfere with serological and microscopic RSD diagnostics, and there is the potential that they may represent new and distinct pathologies of sugarcane.
\end{abstract}

Leifsonia xyli subsp. xyli (Davis et al. 1984; Evtushenko et al. 2000 ) is a bacterium that causes ratoon stunting disease (RSD) of sugarcane (Saccharum interspecific hybrids) (Steindl 1950). However, $L$. xyli subsp. xyli was not originally associated with the main sugarcane progenitor, S. officinarum. Instead, RSD is thought to represent an adverse reaction of the hybridized host to a natural endophyte of $S$. spontaneum, which was first employed as a hybrid parent in the 1920s (Young 2016). L. xyli subsp. xyli inhabits the xylem vessels, which become occluded with a gum-like substance thought to be part of the general host defense response (Bailey 1977; Davis et al. 1980; Gillaspie et al. 1973; Kao and Damann 1978; Plavsic-Banjac and Maramorosch 1972; Teakle et al. 1973, 1978; Worley and Gillaspie 1975). This impedes water and nutrient transport, leading to stunting, particularly under moisture stress. When basal nodes are sliced longitudinally with a sharp knife, the dark red gum can often be observed as signature red 'commas' in vascular bundles of infected plants (Steindl 1950). Since the discovery of RSD in 1945, there has been no indication for the presence of different strains. This is supported by genetic analysis of a large international collection of $L$. xyli subsp. xyli cultures (Young et al. 2006), and comparative genomics between a Brazilian and a Chinese isolate which concluded that the two isolates were essentially identical (X. Zhang et al. 2016).

L. $x y l i$ subsp. $x y l i$ is a notoriously fastidious organism, whose very existence remained unknown between the discovery of RSD in 1945 and the first observations of an associated bacterium in 1972. Initial efforts to culture or microscopically observe a microorganism failed, and the fact that infected juice retained most of its infectivity after extensive filtering and dilution led researchers to believe the disease was caused by a virus. However, despite some reported breakthroughs (Forbes and Ling 1960; Gillaspie 1970; Gillaspie et al. 1966), no causal virus was identified. In 1972, the first report of an RSD-associated bacterium was made (Gillaspie et al. 1973; Plavsic-Banjac and Maramorosch 1972; Teakle et al. 1973), but the complex culture requirements of the bacterium prevented further characterization until it was successfully isolated in 1980 (Davis et al. 1980).

Corresponding author: A. J. Young; E-mail: anthony.young2@usq.edu.au

Accepted for publication 29 March 2017.

C 2017 The American Phytopathological Society
When the genus Clavibacter was erected to accommodate the RSD pathogen and other members of the poorly-defined 'Coryneform' plant pathogens, $C$. michiganense was selected as the type species (Davis et al. 1984). However, advances in chemotaxonomic and molecular techniques, and the discovery of more closely related species, saw the establishment of the genus Leifsonia, to which the RSD pathogen was transferred (Evtushenko et al. 2000). Other Leifsonia species have been identified in a diverse range of environments, including soil (Dastager et al. 2008; Ganzert et al. 2011; Suzuki et al. 1999), glaciers (Pindi et al. 2009; Reddy et al. 2008), snow (Schuerger and Lee 2015), Antarctic ponds and sediments (Ganzert et al. 2011; Pindi et al. 2009; Reddy et al. 2003), lichens (An et al. 2009), grasses (Davis et al. 1984; Evtushenko et al. 2000; Mills et al. 2001), distilled water (Leifson 1962), and insects (Nishiwaki et al. 2007). Additionally, there have been a number of molecular detections of Leifsonia and possible sister taxa from a range of environmental samples, as revealed by searching the GenBank database of the National Center for Biotechnology Information (NCBI). There are a number of genome assemblies for plant-associated Leifsonia species that have yet to be described.

The closest known relative to $L$. xyli subsp. xyli is $L$. xyli subsp. cynodontis (Davis et al. 1984; Evtushenko et al. 2000). This xylem-limited bacterium was originally isolated from Bermuda grass (Cynodon dactylon) in Taiwan (Davis et al. 1980), where it caused Bermuda grass stunting disease (BSD) under adverse environmental conditions (Davis et al. 1983). While L. xyli subsp. cynodontis has since been identified in Bermuda grass in the U.S.A. (Davis and Augustin 1984) and in a range of grass species in eastern Australia (Mills et al. 2001), like RSD, BSD is not known to occur in nature (Davis et al. 1984). Reciprocal inoculations of these pathogens into their respective nonhosts demonstrate that infectivity is limited (as observed through reduced bacterial titers), and there is little to no stunting (Davis et al. 1980). These observations suggest that infectivity is less dependent on specifically evolved host defenses, but more on the suitability of each host to the respective strains (Davis et al. 1983). Despite uncertainty over their evolutionary origins (Young 2016), both pathogens are well-adapted to their contemporary hosts.

The possibility that undescribed Leifsonia strains may represent a threat to sugarcane production has previously been raised (Young et al. 2006). Likewise, the longstanding dependence on hot water treatment (HWT) of vegetative planting stocks to control RSD may be expected over time to result in the emergence of different strains that are resistant to this selection agent. Although quarantine measures may be expected to detect L. xyli subsp. xyli, other Leifsonia 
strains may be invisible to diagnostics specific for L. xyli subsp. xyli. The current study aimed to determine if any other strains of Leifsonia were associated with sugarcane by applying primers designed to specifically amplify DNA from members of this genus.

\section{Materials and Methods}

Sample collection. Sugarcane fields of unknown infection status were sampled using the leaf sheath biopsy (LSB) PCR diagnostic platform for RSD (Young et al. 2016). Briefly, for each field, this involved pooling 50 leaf sheath biopsies (11 mm diameter), immersing overnight in approximately $5 \mathrm{ml}$ of distilled water, centrifuging a $1.5 \mathrm{ml}$ aliquot, and then using the resulting pellet (resuspended in $50 \mu \mathrm{l}$ of sterile water) as template for PCR. All sampling equipment was cleaned thoroughly with $70 \%$ ethanol and scrubbing between fields. Individual stalks were also sampled from a number of fields by expressing xylem sap under positive pressure as used for standard RSD diagnostics with evaporative binding enzyme immunoassay (EB-EIA) and phase-contrast microscopy (Croft et al. 1994).

A total of 697 fields were sampled using the LSB method between 2013 and 2016 from across varieties and crop classes (e.g., plant, 1st ratoon, etc.) throughout Australian sugarcane production areas, spanning approximately 2,000 km between Mareeba, far north Queensland, to Harwood, northern NSW. In addition, 40 fields were sampled in the East Java region of Indonesia in August 2016. A total of 635 samples of expressed xylem sap collected from Australian sugarcane fields were also analyzed.

Sample processing and PCR conditions. Conventional PCR was conducted using generic primers designed to amplify Leifsonia strains, LayF (5'-AAGGAGCATCTGGCACCC-3') and LayR (5'GGGAGTCACTGGGTCACC-3') (Young 2003) as well as L. xyli subsp. xyli specific primers Cxx1 (5'-CCGAAGTGAGCAGATT GACC-3') and Cxx2 (5'-ACCCTGTGTTGTTTTCAACG-3') (Pan et al. 1998). Additionally, to confirm the presence of L. xyli subsp. $x y l i$, quantitative PCR (qPCR) was conducted on most Australian samples using modified primers, Lxx202FB (5'-CGAACTTAGTA CGCCTGCTTG-3') and Lxx331 (5'-GGATTCGGTTCTCATCTC-3') (Grisham et al. 2007; Young et al. 2016). Conventional PCR was conducted in $25 \mu \mathrm{l}$ volumes, using $12.5 \mu \mathrm{l}$ of $2.5 \times$ Amplitaq Gold 360 mastermix premix (Life Technologies), $1.25 \mu \mathrm{l}$ of $4 \mu \mathrm{M}$ of each primer, $9 \mu \mathrm{l}$ water, and $1 \mu \mathrm{l}$ template. The following thermocycle was performed using a Corbett Palm Pilot Cycler CG1-96: $96^{\circ} \mathrm{C}$ for 5 min, 40 cycles of $95^{\circ} \mathrm{C}$ for $30 \mathrm{~s}, 60^{\circ} \mathrm{C}$ for $15 \mathrm{~s}, 72^{\circ} \mathrm{C}$ for $30 \mathrm{~s}$, then a final extension of $72^{\circ} \mathrm{C}$ for $5 \mathrm{~min}$. A $5-\mu \mathrm{l}$ aliquot was electrophoresed on $1.5 \%$ agarose gels cast and run in 0.5× TBE buffer. Bands were visualized using Gel Red stain and Biorad XR+ gel documentation system. qPCR was conducted as previously described (Young et al. 2016).

DNA sequencing and analysis. A Qiagen PCR clean-up column was used as per the manufacturer's instructions to purify the remaining $20 \mu \mathrm{l}$ of product for all PCR-positive samples. Purified PCR products were subjected to Sanger sequencing using the respective forward and reverse amplification primers. Sequences were aligned using MUSCLE in MEGA6 (Tamura et al. 2013), and a maximum likelihood phylogenetic tree (1,000 replications) was constructed using the Tamura 3-parameter algorithm based on approximately $600 \mathrm{bp}$ of $16 \mathrm{~S}-23 \mathrm{~S}$ rRNA intergenic spacer sequence. The consensus tree was rooted to Clavibacter michiganensis subsp. insidiosus (GenBank accession JN613834), which was selected as an outgroup. A general time reversible model was used to model substitutions, deletions were considered complete, and extensive subtree pruning and regrafting (SPR level 5) was employed.

Bacterial isolation. Microbial culturing was attempted on a range of samples in order to isolate the novel strains detected by PCR and sequencing. The medium employed was M3SC, a modified sugar cane (M-SC) medium (Brumbley et al. 2002; Davis 1980), further modified by the addition of methionine at $1.25 \mathrm{~g} \mathrm{liter}^{-1}$, which has been shown to facilitate enhanced growth for $L$. xyli subsp. xyli (Monteiro-Vitorello et al. 2004). Intensive sampling of four Australian fields that had tested positive for the novel strains was conducted. This involved collecting the stalks, identified by the diagnostic scar left by the LSB device, that had facilitated the initial detection. These were scrubbed clean with soapy water, cut into three-eye setts, immersed in $10 \%$ bleach for $10 \mathrm{~min}$, rinsed with distilled water, then immersed in distilled water for $10 \mathrm{~min}$. These were then dried with paper towel, sprayed with $70 \%$ ethanol, and flame sterilized. The distal nodes were aseptically removed and the xylem contents from the central node were expressed under positive pressure in a laminar flow cabinet. These xylem sap samples were subjected to PCR using Leifsonia-generic primers. In all fields, slicing was conducted to determine the presence or absence of internal symptoms that are consistent with RSD.

A $100 \mu \mathrm{l}$ aliquot of all xylem sap samples was spread onto M3SC plates using a sterilized glass spreader. These plates were wrapped in Parafilm and incubated at $28^{\circ} \mathrm{C}$ for approximately 2 weeks. Individual representative colonies were swirled in $100 \mu \mathrm{l}$ of sterile water and restreaked onto fresh M3SC plates from all primary isolation plates corresponding to xylem samples that tested positive using the Leifsoniageneric primers. In turn, the bacterial suspensions were tested using Leifsonia-generic primers to identify target subcultures.

Additionally, isolations were attempted from individual LSB templates that were positive using the Leifsonia-generic primers. This involved adding $10 \mu \mathrm{l}$ of the LSB template into $90 \mu \mathrm{l}$ of sterile water, then spreading onto M3SC medium. Individual colonies were picked and placed into $100 \mu \mathrm{l}$ sterile water as before, but PCR was only conducted on Gram positive isolates, determined after Gram staining of $10 \mu l$ of each respective water suspension. For any target isolate, the

Table 1. Summary of leaf sheath biopsy (LSB) samples taken from Australian and East Java canefields, with Leifsonia xyli subsp. xyli (Lxx) detections and non-Lxx strain detections using the LayF and LayR Leifsonia-generic primer sets

\begin{tabular}{llccc}
\hline Year & Region & Samples & Lxx & Other \\
\hline 2013 & Broadwater & 2 & 1 & 1 \\
2013 & Harwood & 31 & 13 & 7 \\
2014 & Harwood & 244 & 27 & 25 \\
2014 & Maryborough & 3 & 2 & 1 \\
2015 & Broadwater & 44 & 5 & 5 \\
2015 & Bundaberg & 20 & 3 & 7 \\
2015 & Burdekin & 21 & 5 & 2 \\
2015 & Childers & 43 & 7 & 6 \\
2015 & Condong & 14 & 0 & 4 \\
2015 & Harwood & 190 & 16 & 28 \\
2015 & Herbert & 5 & 5 & 0 \\
2015 & Mackay & 14 & 4 & 3 \\
2015 & Maryborough & 10 & 6 & 0 \\
2015 & Plane Creek & 6 & 2 & 8 \\
2015 & Tablelands & 21 & 0 & 2 \\
2016 & Bundaberg & 3 & 1 & 4 \\
2016 & Childers & 10 & 3 & 3 \\
2016 & Harwood & 11 & 5 & 1 \\
2016 & Maryborough & 5 & 1 & 7 \\
2016 & East Java & 40 & 20 & $\mathbf{1 1 6}(\mathbf{1 6 \% )}$ \\
Total & & $\mathbf{7 3 7}$ & $\mathbf{1 2 6}(\mathbf{1 7 \%})$ &
\end{tabular}

Table 2. Summary of xylem sap detections of Leifsonia xyli subsp. xyli (Lxx) and related strain detections using the LayF and LayR Leifsonia-generic primer sets

\begin{tabular}{llccc}
\hline Year & Region & Samples & $\boldsymbol{L x} \boldsymbol{x}$ & Other \\
\hline 2013 & Broadwater & 20 & 8 & 2 \\
2014 & Harwood & 400 & 26 & 4 \\
2015 & Harwood & 20 & 0 & 1 \\
2016 & Bundaberg & 22 & 0 & 0 \\
2016 & Childers & 100 & 19 & 2 \\
2016 & Harwood & 39 & 0 & 1 \\
2016 & Maryborough & 34 & 0 & 7 \\
Total & & $\mathbf{6 3 5}$ & $\mathbf{5 3}(\mathbf{8 \%})$ & $\mathbf{1 7}(\mathbf{3 \%})$ \\
\hline
\end{tabular}


16S rRNA gene was amplified using the primers F27 and R1492 (Lane 1991) and sequenced as above.

\section{Results}

Sample collection. Between 2013 and 2016, LSB samples from a total of 697 fields from Australia were analyzed for the presence of L. xyli subsp. xyli using specific primers (Grisham et al. 2007;
Pan et al. 1998; Young et al. 2016), or other Leifsonia using Leifsoniageneric primers (Young 2003) (Table 1). L. xyli subsp. xyli were detected in 106 fields, while novel strains were detected in 109 fields. From the 40 Indonesian fields tested with LSB-PCR using conventional PCR primers (Pan et al. 1998), 20 were infected with $L . x y l i$ subsp. xyli, while seven had a novel strain present, revealed by the Leifsonia-generic primers. Additionally, 635 xylem sap samples

Table 3. Genomic DNA sequences of 37 genotypes and GenBank accession numbers of amplicons generated from sugarcane samples collected from different varieties, years, regions, and countries

\begin{tabular}{|c|c|c|c|c|c|c|c|}
\hline Sample ${ }^{\mathbf{a}}$ & Variety $^{\mathbf{b}}$ & Type $^{c}$ & Year & Region & Country & Genotype & GenBank \\
\hline PB15-017 & Q183 & LSB & 2015 & Burdekin, QLD & Australia & L1a & KY352955 \\
\hline PB15-031 & Q240 & LSB & 2015 & Childers, QLD & Australia & L1a & KY352956 \\
\hline H16-013 & Q240 & LSB & 2016 & Childers, QLD & Australia & L1a & KY352957 \\
\hline LSB14-051 & Q208 & LSB & 2014 & Harwood, NSW & Australia & L1a & KY352958 \\
\hline LSB14-053 & Q208 & LSB & 2014 & Harwood, NSW & Australia & L1a & KY352959 \\
\hline XS14-517 & Arris & XS & 2014 & Harwood, NSW & Australia & L1a & KY352960 \\
\hline M16-015 & Q252 & LSB & 2016 & Maryborough, QLD & Australia & L1a & KY352961 \\
\hline LSB13-028 & KQ228 & LSB & 2013 & Harwood, NSW & Australia & L1b & KY352962 \\
\hline LSB16-J3 & S. sinensis & LSB & 2016 & East Java & Indonesia & L1c & KY352963 \\
\hline LSB16-J8 & PS862 & LSB & 2016 & East Java & Indonesia & L1d & KY352964 \\
\hline LSB16-J16 & $\mathrm{BL}$ & LSB & 2016 & East Java & Indonesia & L1e & KY352965 \\
\hline PB15-037 & KQ228 & LSB & 2015 & Childers, QLD & Australia & L2a & KY352966 \\
\hline LSB16-J18 & KK & LSB & 2016 & East Java & Indonesia & L2a & KY352967 \\
\hline LSB14-197 & Q240 & LSB & 2014 & Harwood, NSW & Australia & L2a & KY352968 \\
\hline XS15-A50 & BN83-3120 & XS & 2015 & Harwood, NSW & Australia & L2a & KY352969 \\
\hline PB15-069 & Q238 & LSB & 2015 & Mackay, QLD & Australia & L2a & KY352970 \\
\hline M16-010 & Q238 & LSB & 2016 & Maryborough, QLD & Australia & L2a & KY352971 \\
\hline M16-020 & Q232 & LSB & 2016 & Maryborough, QLD & Australia & $\mathrm{L} 2 \mathrm{~b}$ & KY352972 \\
\hline XS14-422 & Q243 & $\mathrm{XS}$ & 2014 & Harwood, NSW & Australia & L3a & KY352973 \\
\hline XS14-423 & Q243 & $\mathrm{XS}$ & 2014 & Harwood, NSW & Australia & L3a & KY352974 \\
\hline $2016-9$ & Q208 & LSB & 2016 & Harwood, NSW & Australia & L3a & KY352975 \\
\hline LSB16-MF-01 & QS06-696 & LSB & 2016 & Harwood, NSW & Australia & L4a & KY352976 \\
\hline XS15-B37 & Q232 & XS & 2015 & Harwood, NSW & Australia & $\mathrm{L} 4 \mathrm{~b}$ & KY352977 \\
\hline XS13-MR2 & Q208 & XS & 2013 & Broadwater, NSW & Australia & L5a & KY352978 \\
\hline PB15-036 & Q208 & LSB & 2015 & Childers, QLD & Australia & L5a & KY352979 \\
\hline LSB14-010 & Q243 & LSB & 2014 & Harwood, NSW & Australia & L5a & KY352980 \\
\hline PB15-056 & Q208 & LSB & 2015 & Maryborough, QLD & Australia & $\mathrm{L} 5 \mathrm{~b}$ & KY352981 \\
\hline LSB14-064 & Q208 & LSB & 2014 & Harwood, NSW & Australia & L5c & KY352982 \\
\hline PB15-085 & KQ228 & LSB & 2015 & Tablelands, QLD & Australia & L5d & KY352983 \\
\hline PB15-097 & Q232 & LSB & 2015 & Bundaberg, QLD & Australia & L5e & KY352984 \\
\hline LSB14-046 & BN83-3120 & LSB & 2014 & Harwood, NSW & Australia & L5f & KY352985 \\
\hline LSB13-007 & Q232 & LSB & 2013 & Harwood, NSW & Australia & L6a & KY352986 \\
\hline PB15-039 & $\mathrm{Q} 250$ & LSB & 2015 & Tablelands, QLD & Australia & L6a & KY352987 \\
\hline LSB16-J23 & $\mathrm{N} 114 \mathrm{~T}$ & LSB & 2016 & East Java & Indonesia & L6b & KY352988 \\
\hline H16-014 & Q238 & LSB & 2016 & Childers, QLD & Australia & L6c & KY352989 \\
\hline LSB13-029 & Q232 & LSB & 2013 & Harwood, NSW & Australia & L6d & KY352990 \\
\hline LSB16-J36 & PSJT & LSB & 2016 & East Java & Indonesia & N1a & KY352991 \\
\hline LSB16-J11 & S. spontaneum & LSB & 2016 & East Java & Indonesia & N1b & KY352992 \\
\hline H16-023 & Q248 & LSB & 2016 & Childers, QLD & Australia & N1c & KY352993 \\
\hline LSB15-190 & Q208 & LSB & 2015 & Harwood, NSW & Australia & $\mathrm{N} 2 \mathrm{a}$ & KY352994 \\
\hline XS14-308 & BN83-3120 & XS & 2014 & Harwood, NSW & Australia & $\mathrm{N} 2 \mathrm{~b}$ & KY352995 \\
\hline H16-054 & Q240 & LSB & 2016 & Harwood, NSW & Australia & $\mathrm{N} 2 \mathrm{c}$ & KY352996 \\
\hline XS14-478 & BN83-3120 & XS & 2014 & Harwood, NSW & Australia & $\mathrm{N} 2 \mathrm{~d}$ & KY352997 \\
\hline LSB14-165 & Arris & LSB & 2014 & Harwood, NSW & Australia & $\mathrm{N} 2 \mathrm{e}$ & KY352998 \\
\hline PB15-049 & Q238 & LSB & 2015 & Childers, QLD & Australia & $\mathrm{N} 3 \mathrm{a}$ & KY352999 \\
\hline PB15-071 & Q240 & LSB & 2015 & Mackay, QLD & Australia & $\mathrm{N} 3 \mathrm{a}$ & KY353000 \\
\hline PB15-058 & Q238 & LSB & 2015 & Maryborough, QLD & Australia & $\mathrm{N} 3 \mathrm{a}$ & KY353001 \\
\hline M16-030 & Q240 & LSB & 2016 & Maryborough, QLD & Australia & $\mathrm{N} 3 \mathrm{~b}$ & KY353002 \\
\hline$* \mathrm{H} 15-031$ & Q183 & Culture & 2015 & Harwood, NSW & Australia & $\mathrm{N} 3 \mathrm{c}$ & KY353010 \\
\hline M16-029 & Q138 & LSB & 2016 & Maryborough, QLD & Australia & $\mathrm{N} 3 \mathrm{~d}$ & KY353003 \\
\hline PB15-080 & Q208 & LSB & 2015 & Te Kowai, QLD & Australia & $\mathrm{N} 3 \mathrm{e}$ & KY353004 \\
\hline PB15-135 & Q245 & LSB & 2015 & Childers, QLD & Australia & N3f & KY353005 \\
\hline M16-071 & Q248 & LSB & 2016 & Maryborough, QLD & Australia & $\mathrm{N} 3 \mathrm{~g}$ & KY353006 \\
\hline LSB14-033M & Q232 & LSB & 2014 & Harwood, NSW & Australia & $\mathrm{N} 3 \mathrm{~h}$ & KY353007 \\
\hline LSB14-205 & Q203 & LSB & 2014 & Harwood, NSW & Australia & $\mathrm{N} 3 \mathrm{i}$ & KY353008 \\
\hline PB15-096 & Q240 & LSB & 2015 & Bundaberg, QLD & Australia & $L x x$ & KY353009 \\
\hline
\end{tabular}

a (*) indicates sugarcane LSB sample from field where a bacterial strain was isolated.

b All varieties tested were interspecific hybrids of Saccharum, excepting S. sinensis and S. spontaneum indicated.

${ }^{\mathrm{c}}$ Refers to PCR from leaf sheath biopsies (LSB), expressed xylem sap (XS), or culture. 
collected from Australian sugarcane fields were analyzed, with $L$. xyli subsp. xyli detected in 53 samples, and related bacteria in 17 samples (Table 2). Using $\chi^{2}$ statistical testing, relative to the novel strains, there was a significantly $(P=0.00001)$ higher detection rate for $L$. xyli subsp. $x y l i$ in expressed xylem sap samples in Australia, while there was no significant difference observed from LSB samples.
Sequence analysis. A total of 56 sequences, representing 37 distinct genotypes, were obtained by Sanger sequencing using the respective forward and reverse primers for the Leifsonia-generic PCR products. Of these, six genotypes were present in two or more samples (Table 3). In addition to the 56 sequences of the novel strains, 24 sequences for $L$. xyli subsp. xyli were obtained, each with

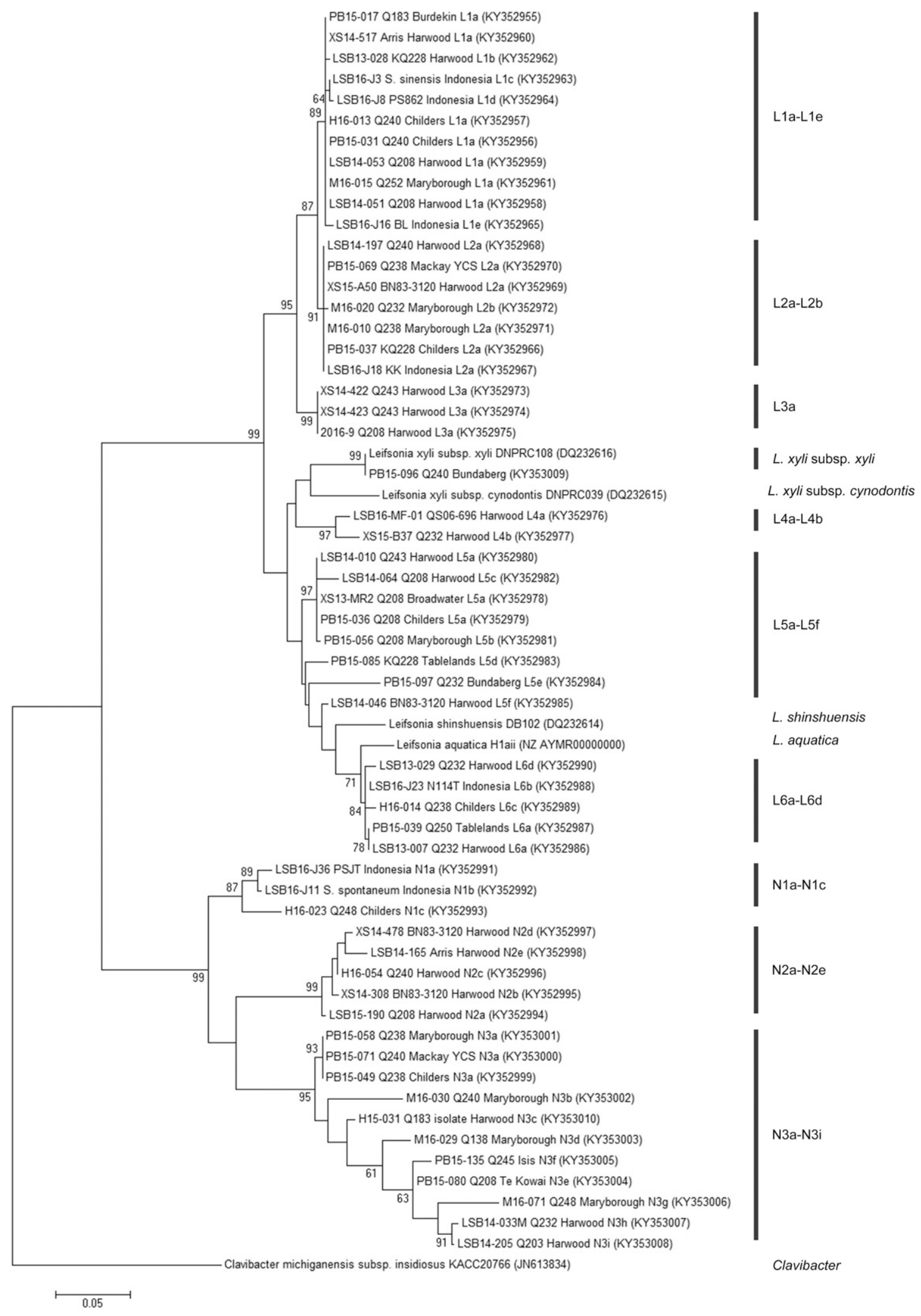

Fig. 1. Maximum likelihood tree based on IGS sequences obtained in this study and reference sequences. Clavibacter michiganensis subsp. insidiosis KACC20766 was used as an outgroup. The phylogenetic tree was tested by 1,000 bootstrap replications, with node support greater than $50 \%$ indicated. Scale indicates the relative number of substitutions at each site. Groups of genotypes correspond with those presented in Table 3. 
$100 \%$ homology to the published sequence of L. xyli subsp. xyli isolate DNPRC108 (GenBank accession DQ232616) (Young et al. 2006) (data not shown). In multiple cases, the presence of more than one amplicon using the Leifsonia-generic primers prevented the acquisition of the DNA sequence. All sequences have been deposited in GenBank with accessions listed in Table 3.

Phylogenetic analysis of the IGS sequences revealed the presence of two distinct groups among the novel strains detected (Fig. 1). The first group comprised genotypes that formed a monophyletic clade with other Leifsonia strains (hereafter referred to as novel Leifsonia strains), while the second was a genetically diverse group from one or more related genera (hereafter referred to as non-Leifsonia strains). For convenience, genotypes belonging to Leifsonia were annotated 'L', while the second clade were annotated 'N' (Table 3, Fig. 1), with major and minor genotypes annotated numerically and alphabetically, respectively.

Bacterial isolation. No putative Leifsonia strains were isolated from LSB templates or expressed xylem sap. However, from one field of variety Q183 at Harwood (corresponding to LSB sample H15-31), a bacterium was isolated from expressed xylem sap that consistently produced an amplicon using the Leifsonia-generic primers. This bacterium was clearly distinguishable from $L$. xyli subsp. $x y l i$ based on its yellow pigment and production of visible single colonies in only 5 days on several media formulations, including M3SC, nutrient agar, CPG, and King's Medium B. Several stalks of cane from this field exhibited RSD-like internal symptoms when basal nodes were sliced with a sharp knife (Fig. 2). Comparison of the $16 \mathrm{~S}$ rRNA gene for this bacterium with other members of the Microbacteriaceae (Table 4) suggests that this group of genotypes may belong to one of two newly erected genera: Cnuibacter (Zhou et al. 2016) or Allohumibacter (Y. R. Kim et al. 2016) (Fig. 3).

\section{Discussion}

This is the first specific report of Leifsonia strains other than L. xyli subsp. xyli associated with sugarcane. A total of 37 distinct genotypes were detected in this study, of which 20 were phylogenetically associated with Leifsonia, while 17 appeared to belong to a related genus (Fig. 1). Five of the novel Leifsonia genotypes were identified in two or more samples, often from different sugarcane varieties growing in different regions and in different years. Although there is no evidence yet that suggests any of these bacteria are causing disease, the presence of RSD-like internal symptoms in stalks from fields where they were detected, their close relationship to a known major sugarcane pathogen, and their identification in all areas sampled, makes their further characterization a priority.

Several research groups have investigated the possibility that L. xyli subsp. xyli may be hosted by grasses (Mills et al. 2001; Rao et al. 1990; Zavaglia et al. 2016), but this is the first investigation into the possibility that different Leifsonia species may be associated with sugarcane. While Young et al. (2006) found no genetic variation in a worldwide collection of $L$. xyli subsp. xyli, they inadvertently imposed a selective constraint by analyzing PCR-confirmed isolates, which may simply have represented a dominant culturable strain of Leifsonia. Although the possibility that other Leifsonia strains may enter into sugarcane was previously noted (Young 2003; Young et al. 2006), it was not suspected that this may already have occurred. However, given the abundance, geographic range, and diversity of Leifsonia genotypes revealed in this study, it is clear that they have been associated with sugarcane for a considerable period. Based on its $16 \mathrm{~S}$ sequence and phylogenetic placement relative to other Leifsonia species, it is possible that an isolate from sugarcane in Brazil (Sugarcane endophyte CTC35, Fig. 3), may correspond to one of the novel strains identified in this study (Zavaglia et al. 2016). However, this can only be confirmed by sequencing the 16S rRNA-23S rRNA intergenic spacer (IGS) locus of this strain, or by the successful culture and characterization of the Australian and Indonesian strains reported here. In addition to further delimiting their occurrence and epidemiological significance throughout the world's sugar industries, it is necessary to confirm that they are in fact associated with sugarcane, and not environmental or sample processing artifacts.

Given that the majority of described Leifsonia species were originally isolated from environmental samples, an obvious consideration is whether the novel strains discovered in this study are truly associated with sugarcane or represent sample contamination. By way of illustration, L. aquatica was originally isolated from distilled water (Leifson 1962), but has since been reported in human clinical studies (Porte et al. 2012), and it is possible that the distilled water used for preparation of LSB templates may have been contaminated.
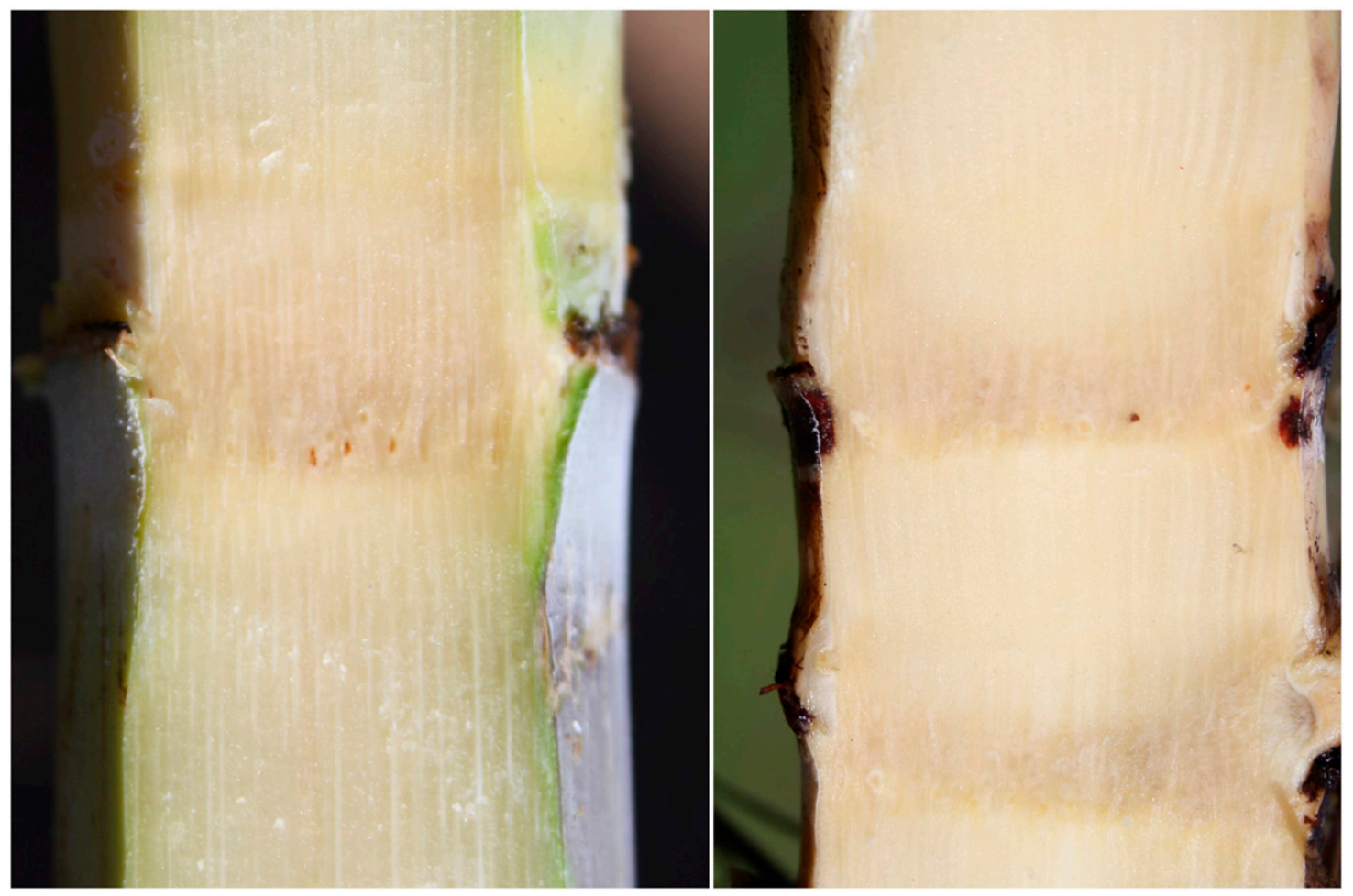

Fig. 2. Internal discoloration in sugarcane variety Q183 caused by Leifsonia xyli subsp. xyli (left) and Microbacteriaceae isolate H15-31 (right). 
However, this can be forcibly discounted as none of the strains detected correspond to L. aquatica, and it would be expected that, contrary to the observations, a single genotype would be amplified from all samples in a given consignment if contaminated water was used in sample preparation. In one field, for example, two sugarcane varieties were growing side-by-side, with one (sample PB15-031) yielding one genotype (L1a), and the other (sample PB15-037) yielding a distinct genotype (L2a). The majority of samples were negative for any Leifsonia, while positive samples often represented $L$. xyli subsp. $x y l i$, or novel strains, and occasionally both. Therefore, it is highly unlikely that the source of the novel strains was the water used in sample processing.
It is also possible that many of the novel strains were simply on the surface of the leaf sheaths and were thus an artifact of the sampling regime. However, by its efficient ability to detect xylem-inhabiting L. xyli subsp. xyli, LSB template preparation has been shown to be effective at concentrating bacteria that occupy the xylem vessels (Young et al. 2014, 2016), and therefore it is not unlikely that the novel strains detected in this study were also xylem-inhabiting. Further support for this is the fact that four Leifsonia genotypes were represented both by LSB samples as well as amplicons generated from expressed xylem sap, to which no water was added, and for which the potential for environmental contamination must be minimal. Likewise, the putative new species detected first by an LSB sample,

Table 4. Bacterial species and strains, GenBank accession, habitat, and sources used in 16S rRNA phylogeny

\begin{tabular}{|c|c|c|c|c|c|}
\hline Species $^{\mathbf{a}}$ & Strain & Genbank accession & Habitat & Region & Reference \\
\hline Actinobacterium sp. & PC7 & AY372902 & Marine sponge & Australia & Lafi et al. 2005 \\
\hline Agrococcus carboniz $^{\mathrm{T}}$ & G4 & GQ504748 & Coal mine & India & Dhanjal et al. 2011 \\
\hline Agrococcus casei $^{\mathrm{T}}$ & LMG22410 & DQ168427 & Cheese & Ireland & Bora et al. 2007 \\
\hline Agrococcus jenensis ${ }^{\mathrm{GT}}$ & DSM9580 & NR026275 & Compost soil & Germany & Groth et al. 1996 \\
\hline Agrococcus terreus $^{\mathrm{T}}$ & DNG5 & FJ423764 & Forest soil & China & J. Y. Zhang et al. 2010 \\
\hline Agromyces fucosus & NBRC15781 & $\mathrm{AB} 842300$ & Soil & Russia & Hamada et al. 2014 \\
\hline Agromyces luteolus $^{\mathrm{T}}$ & IFO16235 & NR024716 & Mangrove rhizosphere & Japan & Takeuchi and Hatano 2001 \\
\hline Agromyces ramosus $\mathrm{GT}$ & DSM43045 & NR026165 & Soil & U.S.A. & Rainey et al. 1994 \\
\hline Agromyces rhizospherae ${ }^{\mathrm{T}}$ & 14 & NR028610 & Mangrove rhizosphere & Japan & Takeuchi and Hatano 2001 \\
\hline Allohumibacter endophyticus ${ }^{\mathrm{GT}}$ & MWE-A11 & JQ723726 & Mugwort roots & South Korea & Y. R. Kim et al. 2016 \\
\hline Clavibacter michiganensis subsp. insidiosus ${ }^{\mathrm{T}}$ & DSM20157 & AM410695 & Alfalfa wilt & U.S.A. & Stackebrandt et al. 2007 \\
\hline Clavibacter michiganensis subsp. michiganensis $\mathrm{GT}$ & DSM46364 & NR115040 & Tomato canker & U.S.A. & Stackebrandt et al. 2007 \\
\hline Clavibacter michiganensis subsp. nebraskensis & LMG5627 & U09763 & Corn bacterial wilt & U.S.A. & Li and De Boer 1995 \\
\hline Clavibacter michiganensis subsp. tessellarius $^{\mathrm{T}}$ & DSM20741 & AM410693 & Wheat leaf spot & U.S.A. & Stackebrandt et al. 2007 \\
\hline Cnuibacter physcomitrellae $e^{\mathrm{GT}}$ & $\mathrm{XA}$ & KP334124 & Moss & China & Zhou et al. 2016 \\
\hline Colombian sugarcane isolate & DNPRC1034 & DQ232611 & Sugarcane & Colombia & Young et al. 2006 \\
\hline Curtobacterium ammoniigenes & NBRC101790 & AB266598 & Acid sulfate soil & Vietnam & Aizawa et al. 2007 \\
\hline Curtobacterium citreum $^{\mathrm{GT}}$ & DSM20528 & NR115034 & Rice & Japan & Stackebrandt et al. 2007 \\
\hline Curtobacterium flaccumfaciens & LPPA407 & AJ879110 & Phaseolus vulgaris & Spain & González et al. 2005 \\
\hline Curtobacterium pusillum ${ }^{\mathrm{T}}$ & DSM20527T & LN681569 & Oil brine & Japan & $\mathrm{n} / \mathrm{a}$ \\
\hline Diaminobutyricimonas aerilata $\mathrm{GT}$ & $6408 \mathrm{~J}-67$ & NR109607 & Air sample & South Korea & Jang et al. 2012 \\
\hline Diaminobutyricimonas sp. & JC2975 & KP185147 & Grassland & South Korea & $\mathrm{n} / \mathrm{a}$ \\
\hline Herbiconiux flava ${ }^{\mathrm{T}}$ & NBRC $16403 \mathrm{~T}$ & AB583921 & Sedge phyllosphere & Russia & Hamada et al. 2012 \\
\hline Herbiconiux ginsengi ${ }^{\mathrm{GT}}$ & wged11 & DQ473536 & Ginseng roots & China & Behrendt et al. 2011 \\
\hline Herbiconiux moechotypicola ${ }^{\mathrm{T}}$ & RB-62 & NR108436 & Insect gut & South Korea & B.-C. Kim et al. 2012 \\
\hline Herbiconiux solani $^{\mathrm{T}}$ & $\mathrm{K} 134 / 01$ & NR116995 & Potato phyllosphere & Germany & Behrendt et al. 2011 \\
\hline Leifsonia antarctica $^{\mathrm{T}}$ & SPC-20T & AM931710 & Sediment & Antarctica & Pindi et al. 2009 \\
\hline Leifsonia aquatica $\mathrm{GT}$ & VKMAc-1400 & DQ232618 & Distilled water & Russia & Evtushenko et al. 2000 \\
\hline Leifsonia bigeumensis ${ }^{\mathrm{T}}$ & MSL-27 & EF466124 & Soil & South Korea & Dastager et al. 2008 \\
\hline Leifsonia kafniensis ${ }^{\mathrm{T}}$ & KFC-22T & AM889135 & Kafni glacier & India & Pindi et al. 2009 \\
\hline Leifsonia lichenia ${ }^{\mathrm{T}}$ & $2 \mathrm{Sb}$ & NR112644 & Lichen & Japan & An et al. 2009 \\
\hline Leifsonia naganoensis ${ }^{\mathrm{T}}$ & DB103 & NR043662 & Soil & Japan & Suzuki et al. 1999 \\
\hline Leifsonia pindariensis ${ }^{\mathrm{T}}$ & PON10T & AM900767 & Pindari glacier & India & Reddy et al. 2008 \\
\hline Leifsonia psychrotolerans ${ }^{\mathrm{T}}$ & LI1 & GQ406810 & Soil & Antarctica & Ganzert et al. 2011 \\
\hline Leifsonia poae $^{\mathrm{T}}$ & VKMAc-1401 & NR028739 & Annual grass & Russia & Evtushenko et al. 2000 \\
\hline Leifsonia rubra ${ }^{\mathrm{T}}$ & CMS76r & AJ438585 & Pond & Antarctica & Reddy et al. 2003 \\
\hline Leifsonia shinshuensis ${ }^{\mathrm{T}}$ & DB102 & DQ232614 & Soil & Japan & Suzuki et al. 1999 \\
\hline Leifsonia xyli subsp. cynodontis & DNPRC039 & DQ232615 & Rhodes Grass & Australia & Young et al. 2006 \\
\hline Leifsonia xyli subsp. xyli & DNPRC108 & DQ232616 & Sugarcane & Australia & Young et al. 2006 \\
\hline Lysinimonas soli ${ }^{\mathrm{GT}}$ & SGM3-12 & JN378395 & Soil & South Korea & Jang et al. 2013 \\
\hline Microbacterium aurantiacum $^{\mathrm{T}}$ & IFO 15234 & AB004726 & Sewage & Japan & Takeuchi and Hatano 1998 \\
\hline Microbacterium hominis ${ }^{\mathrm{T}}$ & IFO 15708 & AB004727 & Clinical & Japan & Takeuchi and Hatano 1998 \\
\hline Microbacterium lacticum ${ }^{\mathrm{GT}}$ & DSM20427 & X77441 & Pasteurized egg & Britain & Rainey et al. 1994 \\
\hline Microbacterium oxydans & B5 & DQ350825 & Soil & China & Mei et al. 2009 \\
\hline Microbacterium testaceum & StLB037 & NR074641 & Potato leaves & Japan & Morohoshi et al. 2011 \\
\hline Mycobacterium kansaii & DSM 43224 & X15916 & Environmental & U.S.A. & Edwards et al. 1989 \\
\hline Putative Agromyces sp. & VKMAc-1802 & DQ232617 & Soil & Russia & Young et al. 2006 \\
\hline Rathayibacter festucae ${ }^{\mathrm{T}}$ & DSM15932 & AM410683 & Grass & Russia & Stackebrandt et al. 2007 \\
\hline Rathayibacter rathayi ${ }^{\mathrm{GT}}$ & DSM7485 & NR026159 & Grass & Unknown & Rainey et al. 1994 \\
\hline Rathayibacter toxicus ${ }^{\mathrm{T}}$ & JCM 9669 & D84127 & Grass & Australia & Sasaki et al. 1998 \\
\hline Rathayibacter tritici $^{\mathrm{T}}$ & DSM7486 & AM410685 & Wheat & Australia & Stackebrandt et al. 2007 \\
\hline Sugarcane endophyte & CTC35 & KX262694 & Sugarcane & Brazil & Zavaglia et al. 2016 \\
\hline Microbacteriaceae isolate & H15-31 & KY353010 & Sugarcane & Australia & This study \\
\hline
\end{tabular}

a Type strains are indicated by ${ }^{\mathrm{T}}$, and genus type strains are designated ${ }^{\mathrm{GT}}$. 
and then isolated from expressed xylem sap from one of the originally sampled stalks in this study, demonstrates in this case at least that the bacterium detected by LSB-PCR was, like L. xyli subsp. $x y l i$, inhabiting the xylem vessels.

Likewise, it is possible that some of these strains represent independent environmental acquisitions. However, this seems highly unlikely given that identical genotypes have been detected across varieties, regions, and years. For example, the L2a genotype (Table 3) was identified over three years in four different varieties in four widely separated regions in Australia, from both LSB samples and a xylem sap sample, as well as an LSB sample from a sugarcane field in Indonesia. Of possible epidemiological significance, one of the

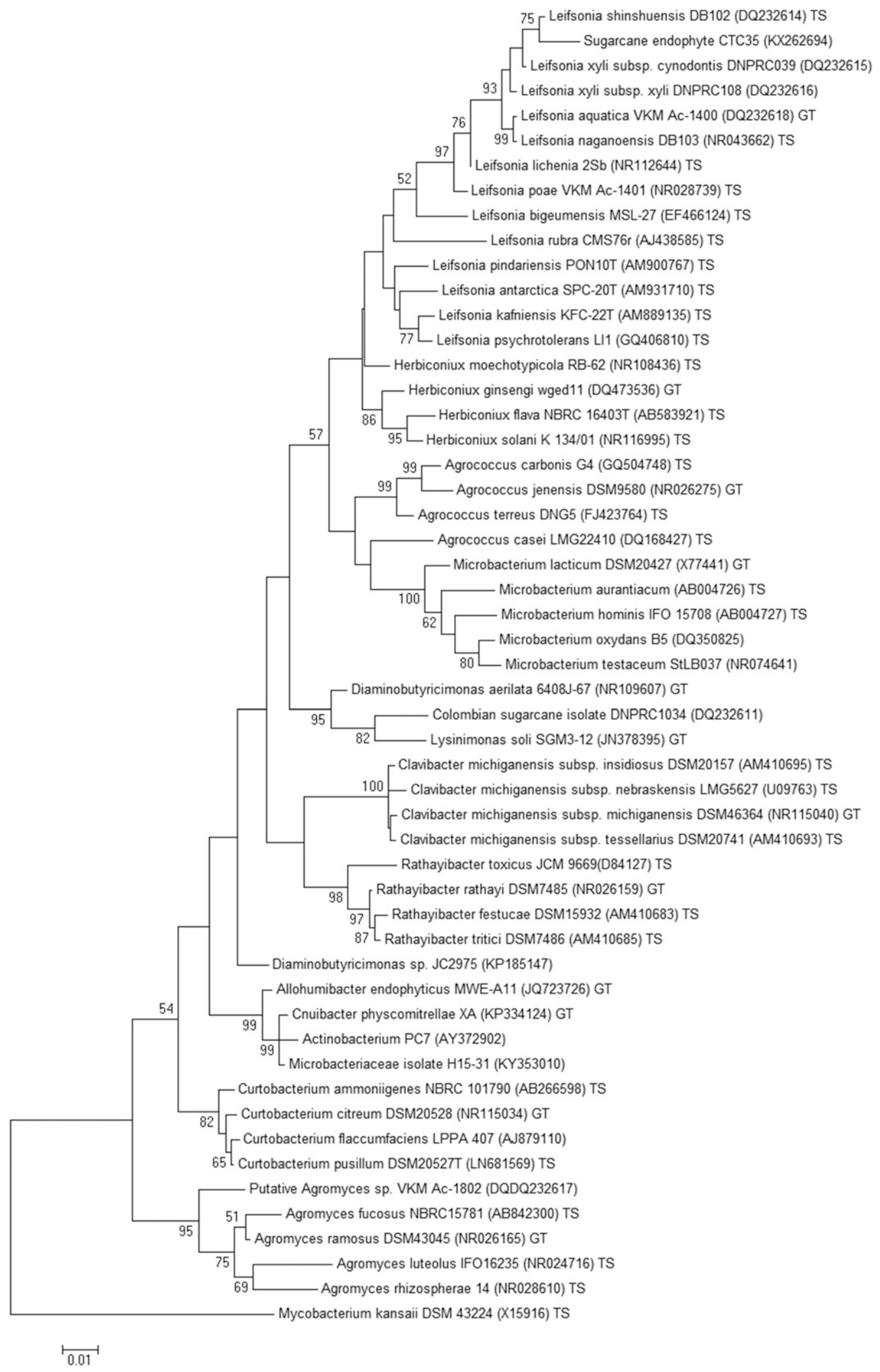

Fig. 3. Maximum likelihood tree based on 16S rRNA sequences of Microbacteriaceae strains listed in Table 4. Mycobacterium kansaii DSM43224 was selected as an outgroup. The phylogenetic tree was tested by 1,000 bootstrap replications, with node support greater than $50 \%$ indicated. Scale indicates the relative number of substitutions at each site. TS = type strain, GT = genus type. 
Australian sugarcane fields it was identified in was affected by yellow canopy syndrome (YCS). The L6a genotype was identified in Q232 growing at Harwood, NSW, in 2013 as well as in Q252 growing 2,000 km away at the Tablelands, Queensland, in 2015. From the one sugarcane field, two separate xylem sap samples (XS14-422 and XS14-423) yielded identical genotypes (L3a), indicating that they are occurring in more than one sugarcane stalk, while the same genotype was identified in an LSB sample from a different sugarcane variety on a separate farm 2 years later. One Australian field was sampled in two consecutive years, with the L1a genotype detected both times. That these novel strains are genuinely associated with sugarcane is more likely than that they represent multiple independent environmental acquisitions.

Of interest is the detection of a wide variety of bacteria from two separate groups: the first conforming with known Leifsonia species, and the second forming a distinct cluster. While the generic primers used in this study were designed to specifically amplify DNA from Leifsonia to the exclusion of related genera such as Clavibacter, Rathayibacter, Agromyces, and Agrococcus (Young 2003), there must be sufficient homology at the primer binding sites to amplify DNA from the non-Leifsonia strains revealed here. Further resolution of this second cluster was achieved by sequence analysis of the $16 \mathrm{~S}$ rRNA gene of the one strain that was recovered from sugarcane. This strain is most closely related to Cnuibacter physcomitrellae, a newly described member of the Microbacteriaceae isolated from moss in China (Zhou et al. 2016). Another close relative, Allohumibacter endophyticus, was isolated from mugwort in South Korea (Y. R. $\mathrm{Kim}$ et al. 2016). The near simultaneous erection of these closely related genera may have inadvertently introduced confusion to an already complex taxonomic arrangement (Fig. 3). As the ribosomal IGS sequences for these novel genera have not been obtained, further phylogenetic resolution of the novel strains detected in the current study cannot yet be achieved.

There was a marked difference in the detection rate of the novel strains between LSB and xylem sap samples. Of the 737 fields tested using LSB-PCR, $16 \%$ recorded the presence of a novel strain, while they were only detected in $3 \%$ of the 635 xylem sap samples analyzed. The lower detection rate must in part reflect the more effective LSB sampling strategy, as it has been demonstrated that diagnostics applied to expressed xylem are a relatively ineffective way of detecting L. xyli subsp. xyli (Young et al. 2016). However, with similar incidence rates of $L$. xyli subsp. xyli and the novel strains based on LSB samples, there was a higher rate of $L$. xyli subsp. xyli detections in the xylem sap samples. This may suggest higher relative $L$. xyli subsp. $x y l i$ titers, and consequently higher detection rates, because this bacterium is relatively more adapted to the sugarcane host. Furthermore, this may explain why, with the exception of one instance, efforts to culture any of the novel strains failed. Alternately, some or all of the novel strains may be more fastidious than $L$. xyli subsp. $x y l i$, which itself escaped isolation for such a significant period of time.

There was a significantly higher detection rate of $L$. xyli subsp. xyli in the Indonesian fields relative to the Australian fields. The overall RSD incidence of $50 \%$ in Indonesian fields was determined with conventional PCR using LSB samples, which has been shown to be $50 \%$ less sensitive than LSB-qPCR (Young et al. 2016). Therefore, the actual RSD incidence is likely to be much higher, reflecting the general absence or ineffectiveness of RSD control methods in Indonesia relative to Australia. However, of significant interest is the fact that the incidence of novel Leifsonia and non-Leifsonia strains present in Indonesian samples was not statistically different from the incidence of similar strains in Australia. This suggests that RSD control measures do not influence the incidence of these novel strains, an observation borne out by their detection in approved seed plot cane, and in farm seedbeds grown from approved seed plot cane, in Australia.

While the epidemiological significance of these novel Leifsonia strains is unknown, three were detected after returning false positive EB-EIA and phase contrast microscopy diagnostic results for $L$. xyli subsp. xyli, suggesting that some of them may interfere with serological and microscopic RSD diagnostics (Young et al. 2016). Two of the genotypes, L2a (from sample PB15-069) and N6a (from sample PB15-071), came from fields exhibiting symptoms of the as yet unresolved YCS. The link between moisture stress and starch accumulation associated with both YCS and RSD (Joyce et al. 2016; Steindl 1950) necessitates their exclusion as possible factors.

The origin of the strains discovered in this study is a mystery. Several have been identified in sugarcane fields subject to strict RSD control measures, while one genotype, LSB16-MF-01 (L4a), was identified in an LSB sample collected from a plant improvement trial also subject to hot water treatment (HWT) used in RSD control. Given that standard HWT practices do not eradicate all L. xyli subsp. xyli cells in infected sugarcane (Damann and Benda 1983; Koike et al. 1982; Roach 1987; Victoria et al. 1986), it is possible that it is also not entirely effective against related strains. This may explain why the incidence of the novel strains was similar in Australia and Indonesia, while the L. xyli subsp. xyli incidence was markedly different. As such, international variety exchange and the distribution of new sugarcane clones through variety improvement programs that rely on HWT represent possible pathways for the widespread distribution of diverse strains. It is of concern that possible horizontal gene transfer among these strains may lead to increased genetic diversity among the $L$. xyli subsp. xyli population, potentially compromising resistance breeding efforts. Likewise, there is a chance that among these strains will emerge one that is significantly more resistant to the thermotherapy of planting stocks that represents the single most important RSD control measure. Further efforts to expand the germplasm base of future hybrids may expose the sugar industry to different, previously unrecognized pathogens, that unless looked for, will be discovered too late. Efforts are underway to further characterize these new strains and determine their epidemiological significance.

\section{Acknowledgments}

Part of this work was supported by Sugar Research Australia Grants SRA2014086 and SRA2016-311. We wish to thank Asuka Kawamata, Eleanore Lambley, Alister Smith, and Mark Ensbey for technical assistance with this research, and the various Productivity Services Company personnel who provided samples. We acknowledge the valuable assistance of staff from the Indonesian Sugar Research Institute (ISRI), in particular Lilik Putra and Ari Kristini, who coordinated the collections. Additionally, we wish to thank Julie Harris and her team for assistance in preparing the manuscript.

\section{Literature Cited}

Aizawa, T., Ve, N. B., Kimoto, K., Iwabuchi, N., Sumida, H., Hasegawa, I., Sasaki, S., Tamura, T., Kudo, T., Suzuki, K., Nakajima, M., and Sunairi, M. 2007. Curtobacterium ammoniigenes sp. nov., an ammonia-producing bacterium isolated from plants inhabiting acidic swamps in actual acid sulfate soil areas of Vietnam. Int. J. Syst. Evol. Microbiol. 57:1447-1452.

An, S. Y., Xiao, T., and Yokota, A. 2009. Leifsonia lichenia sp. nov., isolated from lichen in Japan. J. Gen. Appl. Microbiol. 55:339-343.

Bailey, R. A. 1977. The systemic distribution and relative occurrence of bacteria in sugarcane varieties affected by ratoon stunting disease. Proc. S. Afr. Sugar Technol. Assoc. 51:55-56.

Behrendt, U., Schumann, P., Hamada, M., Suzuki, K., Sproer, C., and Ulrich, A 2011. Reclassification of Leifsonia ginsengi (Qiu et al. 2007) as Herbiconiux ginsengi gen. nov., comb. nov. and description of Herbiconiux solani sp. nov., an actinobacterium associated with the phyllosphere of Solanum tuberosum L. Int. J. Syst. Evol. Microbiol. 61:1039-1047.

Bora, N., Vancanneyt, M., Gelsomino, R., Swings, J., Brennan, N., Cogan, T. M. Larpin, S., Desmasures, N., Lechner, F. E., Kroppenstedt, R. M., Ward, A. C., and Goodfellow, M. 2007. Agrococcus casei sp. nov., isolated from the surfaces of smear-ripened cheeses. Int. J. Syst. Evol. Microbiol. 57:92-97.

Brumbley, S. M., Petrasovits, L. A., Birch, R. G., and Taylor, P. W. J. 2002 Transformation and transposon mutagenesis of Leifsonia xyli subsp. xyli, causal organism of ratoon stunting disease of sugarcane. Mol. Plant-Microbe Inter. 15:262-268.

Croft, B. J., Greet, A. D., Leaman, T. M., and Teakle, D. S. 1994. RSD diagnosis and varietal resistance screening in sugarcane using the EB-EIA technique. Aust. Soc. Sugar Cane Technol. 16:143-151.

Damann, K. E., and Benda, G. I. A. 1983. Evaluation of commercial heat-treatment methods for control of ratoon stunting disease of sugarcane. Plant Dis. 67:966-967.

Dastager, S. G., Lee, J. C., Ju, Y. J., Park, D. J., and Kim, C. J. 2008. Leifsonia bigeumensis sp.nov., isolated from soil on Bigeum Island, Korea. Int. J. Syst. Evol. Microbiol. 58:1935-1938.

Davis, M. J., and Augustin, B. J. 1984. Occurrence in Florida of the bacterium that causes Bermuda grass stunting disease. Plant Dis. 68:1095-1097. 
Davis, M. J., Gillaspie, A. G., Jr., Harris, R. W., and Lowson, R. H. 1980. Ratoon stunting disease of sugarcane: Isolation of the causal bacterium. Science 210: 1365-1367.

Davis, M. J., Gillaspie, A. G., Jr., Vidaver, A. K., and Harris, R. W. 1984. Clavibacter: A new genus containing some phytopathogenic coryneform bacteria, including Clavibacter xyli subsp. xyli sp. nov., subsp. nov. and Clavibacter xyli subsp. cynodontis subsp. nov., pathogens that cause ratoon stunting disease of sugarcane and bermudagrass stunting disease. Int. J. Syst. Bacteriol. 34:107-117.

Davis, M. J., Lawson, R. H., Gillaspie, A. G., Jr., and Harris, R. W. 1983. Properties and relationships of two xylem-limited bacteria and a mycoplasmalike organism infecting bermuda grass. Phytopathol. 73:341-346.

Dhanjal, S., Kaur, I., Korpole, S., Schumann, P., Cameotra, S. S., Pukall, R., Klenk, H. P., and Mayilraj, S. 2011. Agrococcus carbonis sp. nov., isolated from soil of a coal mine. Int. J. Syst. Evol. Microbiol. 61:1253-1258.

Edwards, U., Rogall, T., Blocker, H., Emde, M., and Bottger, E. C. 1989. Isolation and direct complete nucleotide determination of entire genes. Characterization of a gene coding for $16 \mathrm{~S}$ ribosomal RNA. Nucleic Acids Res. 17:7843-7853.

Evtushenko, L. I., Dorofeeva, L. V., Subbotin, S. A., Cole, J. R., and Tiedje, J. M. 2000. Leifsonia poae gen. nov., sp. nov., isolated from nematode galls on Poa апnиа, and reclassification of 'Corynebacterium aquaticum' Leifson 1962 as Leifsonia aquatica (ex Leifson 1962) gen. nov., nom. rev., comb. nov. and Clavibacter xyli Davis et al. 1984. with two subspecies as Leifsonia xyli (Davis et al. 1984) gen. nov., comb. nov. Int. J. Syst. Evol. Microbiol. 50:371-380.

Forbes, I. L., and Ling, K. C. 1960. Particles associated with the ratoon stunting disease of sugarcane. Sugar J. 23:2

Ganzert, L., Bajerski, F., Mangelsdorf, K., Lipski, A., and Wagner, D. 2011. Leifsonia psychrotolerans sp. nov., a psychrotolerant species of the family Microbacteriaceae from Livingston Island, Antarctica. Int. J. Syst. Evol. Microbiol. 61:1938-1943.

Gillaspie, A. G., Jr. 1970. Evidence that ratoon stunting disease of sugarcane is caused by virus and not mycoplasma. Phytopathology 60:1448-1450.

Gillaspie, A. G., Jr., Davis, R. E., and Worley, J. F. 1973. Diagnosis of ratoon stunting disease based on the presence of a specific microorganism. Plant Dis. Rep. 57:987-990.

Gillaspie, A. G., Jr., Irvine, J. E., and Steere, R. L. 1966. Ratoon stunting disease virus. Assay technique and partial purification. Phytopathology 56:1426-1427.

González, A. J., Tello, J. C., and Rodicio, M. R. 2005. Bacterial wilt of beans (Phaseolus vulgaris) caused by Curtobacterium flaccumfaciens in Southeastern Spain. Plant Dis. 89:1361.

Grisham, M. P., Pan, Y. B., and Richard, E. P., Jr. 2007. Early detection of Leifsonia xyli subsp. xyli in sugarcane leaves by real-time polymerase chain reaction. Plant Dis. 91:430-434.

Groth, I., Schumann, P., Weiss, N., Martin, K., and Rainey, F. A. 1996. Agrococcus jenensis gen. nov., sp. nov., a new genus of actinomycetes with diaminobutyric acid in the cell wall. Int. J. Syst. Bacteriol. 46:234-239.

Hamada, M., Komukai, C., Tamura, T., Evtushenko, L. I., Vinokurova, N. G., and Suzuki, K. 2012. Description of Herbiconiux flava sp. nov. and emended description of the genus Herbiconiux. Int. J. Syst. Evol. Microbiol. 62:795-799.

Hamada, M., Shibata, C., Ishida, Y., Tamura, T., Yamamura, H., Hayakawa, M., and Suzuki, K. 2014. Agromyces iriomotensis sp. nov. and Agromyces subtropicus sp. nov., isolated from soil. Int. J. Syst. Evol. Microbiol. 64: 833-838.

Jang, Y. H., Kim, S. J., Hamada, M., Tamura, T., Ahn, J. H., Weon, H. Y., Suzuki, K., and Kwon, S. W. 2012. Diaminobutyricimonas aerilata gen. nov., sp. nov., a novel member of the family Microbacteriaceae isolated from an air sample in Korea. J. Microbiol. 50:1047-1052.

Jang, Y. H., Kim, S. J., Tamura, T., Hamada, M., Weon, H. Y., Suzuki, K., Kwon, S. W., and Kim, W. G. 2013. Lysinimonas soli gen. nov., sp. nov., isolated from soil, and reclassification of Leifsonia kribbensis Dastager et al. 2009. as Lysinimonas kribbensis sp. nov., comb. nov. Int. J. Syst. Evol. Microbiol. 63: 1403-1410.

Joyce, P., Don, N. H., Sousa, M., and Olsen, D. 2016. Starch accumulation in sugarcane in response to stress. Proc. Aust. Soc. Sugar Cane Technol. 38:20-28.

Kao, J., and Damann, K. E. 1978. Microcolonies of the bacterium associated with ratoon stunting disease found in sugarcane xylem matrix. Phytopathology 68: 545-551

Kim, B.-C., Park, D.-S., Kim, H., Oh, H.-W., Lee, K. H., Shin, K.-S., and Bae, K. S. 2012. Herbiconiux moechotypicola sp. nov., a xylanolytic bacterium isolated from the gut of hairy long-horned toad beetles, Moechotypa diphysis (Pascoe). Int. J. Syst. Evol. Microbiol. 62:90-95.

Kim, Y. R., Kim, T. S., Han, J. H., Joung, Y., Park, J., and Kim, S. B. 2016. Allohumibacter endophyticus gen. nov., sp. nov., isolated from the root of wild Artemisia princeps (mugwort). Int. J. Syst. Evol. Microbiol. 66: 1823-1827.

Koike, H., Gillaspie, A. G., Jr., and Benda, G. T. A. 1982. Cane yield response to ratoon stunting disease. Int. Sugar J. 84:131-133.

Lafi, F. F., Garson, M. J., and Fuerst, J. A. 2005. Culturable bacterial symbionts isolated from two distinct sponge species (Pseudoceratina clavata and Rhabdastrella globostellata) from the Great Barrier Reef display similar phylogenetic diversity. Microb. Ecol. 50:213-220.

Lane, D. J. 1991. 16S/23S rRNA sequencing. Pages 115-175 in: Nucleic acid techniques in bacterial systematics. E. Stackebrandt and M. Goodfellow, eds. J. Wiley \& Sons, Ltd., Chichester, United Kingdom.
Leifson, E. 1962. The bacterial flora of distilled and stored water. III. New species of the genera Corynebacterium, Flavobacterium, Spirillum and Pseudomonas. Int. Bull. Bacteriol. Nomencl. Taxon. 12:161-170.

Li, X., and De Boer, S. H. 1995. Comparison of 16S ribosomal RNA genes in Clavibacter michiganensis subspecies with other coryneform bacteria. Can. J. Microbiol. 41:925-929.

Mei, Y., He, B., Liu, N., and Ouyang, P. 2009. Screening and distributing features of bacteria with hydantoinase and carbamoylase. Microbiol. Res $164: 322-329$

Mills, L., Leaman, T. M., Taghavi, S. M., Shackel, L., Dominiak, B. C., Taylor, P. W. J., Fegan, M., and Teakle, D. S. 2001. Leifsonia-like bacteria are endophytes of grasses in eastern Australia. Australas. Plant Pathol. 30:145-151.

Monteiro-Vitorello, C. B., Camargo, L. E. A., Van Sluys, M. A., Kitajima, J. P., Truffi, D., do Amaral, A. M., Harakava, R., de Oliveira, J. C. F., Wood, D., de Oliveira, M. C., Miyaki, C., Takita, M. A., da Silva, A. C. R., Furlan, L. R. Carraro, D. M., Camarotte, G., Almeida, N. F., Jr., Carrer, H., Coutinho, L. L., El-Dorry, H. A., Ferro, M. I. T., Gagliardi, P. R., Giglioti, E., Goldman, M. H. S., Goldman, G. H., Kimura, E. T., Ferro, E. S., Kuramae, E. E., Lemos, E. G. M., Lemos, M. V. F., Mauro, S. M. Z., Machado, M. A., Marino, C. L., Menck, C. F., Nunes, L. R., Oliveira, R. C., Pereira, G. G., Siqueira, W., de Souza, A. A., Tsai, S. M., Zanca, A. S., Simpson, A. J. G., Brumbley, S. M., and Setubal, J. C. 2004. The genome sequence of the Gram-positive sugarcane pathogen Leifsonia xyli subsp. xyli. Mol. Plant-Microbe Interact. 17:827-836.

Morohoshi, T., Wang, W. Z., Someya, N., and Ikeda, T. 2011. Genome sequence of Microbacterium testaceum StLB037, an N-acylhomoserine lactone degrading bacterium isolated from potato leaves. J. Bacteriol. 193:2072-2073.

Nishiwaki, H., Ito, K., Shimomura, M., Nakashima, K., and Matsuda, K. 2007. Insecticidal bacteria isolated from predatory larvae of the antlion species Myrmeleon bore (Neuroptera: Myrmeleontidae). J. Invertebr. Pathol. 96: 80-88.

Pan, Y.-B., Grisham, M. P., Burner, D. M., Damann, K. E., Jr., and Wei, Q. 1998 A polymerase chain reaction protocol for the detection of Clavibacter xyli subsp. $x y l i$, the causal bacterium of sugarcane ratoon stunting disease. Plant Dis. 82:285-290.

Pindi, P. K., Kishore, K. H., Reddy, G. S. N., and Shivaji, S. 2009. Description of Leifsonia kafniensis sp. nov. and Leifsonia antarctica sp. nov. Int. J. Syst. Evol. Microbiol. 59:1348-1352.

Plavsic-Banjac, B., and Maramorosch, K. 1972. Electron microscopy of the xylem of ratoon stunted sugarcane. (Abstr.). Phytopathology 62:498-499.

Porte, L., Soto, A., Andrighetti, D., Dabanch, J., Braun, S., Saldivia, A., Flores, J. C. Wozniak, A., Garcia, P., and Weitze, T. 2012. Catheter-associated bloodstream infection caused by Leifsonia aquatica in a haemodialysis patient: a case report. J. Med. Microbiol. 61:868-873.

Rainey, F. A., Weiss, N., Prauser, H., and Stackebrandt, E. 1994. Further evidence for the phylogenetic coherence of actinomycetes with group B-peptidoglycan. FEMS Microbiol. Lett. 118:135-139.

Rao, G. P., Singh, M., and Singh, H. N. 1990. Alternative hosts of sugarcane diseases. Sugar Cane Autumn (Supplement), 8-26.

Reddy, G. S. N., Prabagaran, S. R., and Shivaji, S. 2008. Leifsonia pindariensis $\mathrm{sp}$ nov., isolated from the Pindari glacier of the Indian Himalayas, and emended description of the genus Leifsonia. Int. J. Syst. Evol. Microbiol. 58: 2229-2234.

Reddy, G. S. N., Prakash, J. S. S., Srinivas, R., Matsumoto, G. I., and Shivaji, S. 2003. Leifsonia rubra sp. nov. and Leifsonia aurea sp. nov., psychrophiles from a pond in Antarctica. Int. J. Syst. Evol. Microbiol. 53:977-984.

Roach, B. T. 1987. Observations on the incidence, effects and control of ratoon stunting disease. Proc. Aust. Soc. Sugar Cane Technol. 9:109-116.

Sasaki, J., Chijimatsu, M., and Suzuki, K. 1998. Taxonomic significance of 2,4diaminobutyric acid isomers in the cell wall peptidoglycan of actinomycetes and reclassification of Clavibacter toxicus as Rathayibacter toxicus comb. nov. Int. J. Syst. Bacteriol. 48:403-410.

Schuerger, A., and Lee, P. 2015. Microbial ecology of a crewed rover traverse in the Arctic: low microbial dispersal and implications for planetary protection on human Mars missions. Astrobiol. 15:478-491.

Stackebrandt, E., Brambilla, E., and Richert, K. 2007. Gene sequence phylogenies of the family Microbacteriaceae. Curr. Microbiol. 55:42-46.

Steindl, D. R. S. 1950. Ratoon stunting disease. Proc. Int. Soc. Sugar Cane Technol. 15:210-212.

Suzuki, K., Suzuki, M., Sasaki, J., Park, Y. H., and Komagata, K. 1999. Leifsonia gen. nov., a genus for 2,4-diaminobutyric acid-containing actinomycetes to accommodate "Corynebacterium aquaticum" Leifson 1962 and Clavibacter xyli subsp. cynodontis Davis 1984. J. Gen. Appl. Microbiol. 45:253-262.

Takeuchi, M., and Hatano, K. 1998. Proposal of six new species in the genus Microbacterium and transfer of Flavobacterium marinotypicum ZoBell and Upham to the genus Microbacterium as Microbacterium maritypicum comb. nov. Int. J. Syst. Bacteriol. 48:973-982.

Takeuchi, M., and Hatano, K. 2001. Agromyces luteolus sp. nov., Agromyces rhizospherae sp. nov. and Agromyces bracchium sp. nov., from the mangrove rhizosphere. Int. J. Syst. Evol. Microbiol. 51:1529-1537.

Tamura, K., Stecher, G., Peterson, D., Filipski, A., and Kumar, S. 2013. MEGA6: Molecular Evolutionary Genetics Analysis Version 6.0. Mol. Biol. Evol. 30 $2725-2729$ 
Teakle, D. S., Appleton, J. M., and Steindl, D. R. L. 1978. Anatomical basis for resistance of sugarcane to ratoon stunting disease. Physiol. Plant Pathol. 12: 83-91.

Teakle, D. S., Smith, P. M., and Steindl, D. R. L. 1973. Association of a small coryneform bacterium with the ratoon stunting disease of sugarcane. Aust. Agric. Res. 24:869-874.

Victoria, J. F., Ochoa, O., and Cassale, H. C. 1986. Thermic control of ratoon stunting disease of sugarcane in Colombia. Proc. Int. Soc. Sugar Cane Technol. 19:325-331.

Worley, J. F., and Gillaspie, A. G., Jr. 1975. Electron microscopy in situ of the bacterium associated with ratoon stunting disease in sudangrass. Phytopathol. 65:287-295.

Young, A. J. 2003. Genetic diversity of Leifsonia xyli subsp. xyli, causal agent of ratoon stunting disease of sugarcane. Ph. D. thesis, Macquarie University, North Ryde, NSW, Australia.

Young, A. J. 2016. Possible origin of ratoon stunting disease following interspecific hybridization of Saccharum species. Plant Pathol. 65: 1403-1410.

Young, A. J., Kawamata, A., Lambley, E., Ensbey, M. A., and Nock, C. J. 2016. Diagnosis of sugarcane ratoon stunting disease using PCR on crude templates from pooled leaf sheath biopsies. Plant Dis. 100:2492-2498.
Young, A. J., Nock, C. J., Martin, A., and Ensbey, M. 2014. Novel diagnostic for ratoon stunting disease: development and implications for RSD management. Proc. Aust. Soc. Sugar Cane Technol. 36:237-243.

Young, A. J., Petrasovits, L. A., Croft, B. J., Gillings, M., and Brumbley, S. M. 2006. Genetic uniformity of international isolates of Leifsonia xyli subsp. $x y l i$, causal agent of ratoon stunting disease of sugarcane (Saccharum interspecific hybrids). Aust. Plant Path. 35:503-511.

Zavaglia, A. C., Cia, M. C., Popin, R. V., and Camargo, L. E. A. 2016. No alternative hosts of the sugarcane pathogen Leifsonia xyli subsp. xyli were identified among grass and non-grass species using novel PCR primers. Trop. Plant Pathol. 41:336-339.

Zhang, J. Y., Liu, X. Y., and Liu, S. J. 2010. Agrococcus terreus sp. nov. and Micrococcus terreus sp. nov., isolated from forest soil. Int. J. Syst. Evol. Microbiol. 60:1897-1903.

Zhang, X., Chen, M., Liang, Y., Xing, Y., Yang, L., Chen, M., Comstock, J. C., Li, Y., and Yang, L. 2016. Morphological and physiological responses of sugarcane to Leifsonia xyli subsp. xyli infection. Plant Dis. 100:2499-2506.

Zhou, X., Guo, G. N., Wang, L. Q., Bai, S. L., and Li, Y. H. 2016. Cnuibacter physcomitrellae gen. nov., sp. nov., a novel member of the family Microbacteriaceae isolated from the moss of Physcomitrella patens. Int. J. Syst. Evol. Microbiol. 66:680-688. 